\title{
EDUCAÇÃO, FORMAÇÃO DO CARÁTER E MOTIVAÇÃO MORAL EM PLATÃO
}

\author{
Mário Nogueira de Oliveira \\ Universidade Federal de Ouro Preto
}

\begin{abstract}
Resumo: Este artigo trata filosofia de Platão especificamente abordando a questão da educação vinculada com a formação do caráter moral que possibilita a motivação para a escolha de ações virtuosa por quem aceitou se submeter ao treinamento dialético buscando autoconhecimento e pensamento crítico. 0 artigo pretende apresentar como a dialética platônica é uma forma especialmente apropriada para a compreensão da prática conjunta e simultânea de educação, pensamento crítico, ética e política. Para alcançar estes objetivos analisamos partes de um exemplar de cada tipo de diálogo platônico: o Cármides, como diálogo socrático, a República como um diálogo do período intermediário e o Político como um representante dos diálogos lógicos, último grupo dos diálogos platônicos.
\end{abstract}

Palavras-chave: Platão, Sócrates, Educação, Formação do Caráter Moral, Motivação Moral

Abstract: This article analyses Plato's Philosophy specifically approaching education linked with character formation which constitutes motivation for virtuous choices by someone who has been trained in dialectics. This article intends to present how Education, Critical Thinking, Ethics and Politics are related in Socratic and Platonic dialectics. Our approach is focused in one Socratic dialogue, Charmides, an intermeadiate period dialogue, The Republic, and a logical dialogue, The Statesman.

Keywords: Plato, Socrates, Education, Character Formation, Moral Motivation

\section{Introdução:}

Este artigo apresenta um aspecto específico da Filosofia Política e da Filosofia da Educação de Platão: a formação do caráter moral e a motivação moral para escolhas de ações daquele que passa pelo treinamento dialético típico das práticas filosóficas de Sócrates e Platão. O exercício dialético prepara os jovens não só para se capacitarem no tema de cada diálogo, mas 
para o aprendizado do tema de cada diálogo, mas prepara-os também para vida cívica e o cultivo do intelecto. A educação cívica, que implica um cuidado especial com a psyque, é apresentada como a formação do caráter moral. Este possibilita a motivação necessária para que o jovem possa escolher ações justas e práticas virtuosas.

Considerando o que seria uma prática aproximada ao chamado comunitarismo contemporâneo, Platão trabalha com métodos que levam seu educando a entender que seu melhor interesse é coalescente com o melhor interesse da comunidade, de tal forma que aquilo que geralmente traduzimos como paidéia, educação, pode constituir-se no ensino e cultivo de um modo de viver ético e de pensar criticamente. $\mathrm{O}$ artigo enfoca especialmente os diálogos Cármides, República e Político. E divide-se em partes que analisam as especificidades desse diálogo para o tema geral do artigo. Concluímos argumentando como a filosofia dialética platônica é uma forma especialmente apropriada para a compreensão da prática conjunta e simultânea de educação, pensamento crítico, ética e política.

\section{Educação, formação do caráter e motivação moral em Platão: 0 exemplo do diálogo Cármides.}

Os chamados diálogos socráticos de Platão ensinam-nos que um dos objetivos do homem que não teme o trabalho de investigar sua própria vida e assume a tarefa de sempre colocar em cheque suas crenças mais profundas é buscar e alcançar o bem-estar de sua mente ou psique. Esta atitude contrapõese à resignação preguiçosa de quem teme duvidar daquilo que lhe foi ensinado ou recebido como um valor tradicional a ser preservado. Um tipo de "terapia" da psique aconteceria através do autoexame de suas crenças e valores e do entendimento do significado dos termos éticos que constituem a motivação para nossas ações e são os temas de diversos diálogos platônicos. Entre estes, encontram-se a coragem, a continência, a possibilidade de aprendermos qualquer virtude moral, a amizade e outros.

O fato de serem diálogos já implica que o conhecimento adquirido resulta de um método de pesquisa comum, ou seja, perguntas e respostas entre duas pessoas, geralmente educador e educando, que agem em um espírito de ajuda mútua e amizade. Platão deixou claro que o debate deve ocorrer em um ambiente de amizade para que o conhecimento adquirido seja a própria vitória, não havendo debatedores vencedores ou perdedores. Este 
ponto torna-se mais especial quando consideramos que muitas vezes no nosso trabalho cotidiano de filósofos discordamos entre nós e o que deveria ser a busca do argumento cogente torna-se uma disputa pessoal ou uma disputa entre escolas ou tradições filosóficas. Para estes equívocos na prática da filosofia, a história da filosofia platônica ajuda-nos a colocar nossa visão em uma perspectiva melhor. Sobre o trabalho em conjunto, Xenofonte, uma das fontes doxográficas para tentarmos entender a prática filosófica de Sócrates, explicou-nos que a palavra dialética, derivada de dialégesthai, foi um termo originalmente usado para designar a função do diálogo de conferir alguma coisa com outrem: chegar juntos e conferir, um com o outro, alguma coisa (Mem. IV, 5, 12). Assim, a história da filosofia mais uma vez nos mostra que "chegamos juntos ao conhecimento" ao invés de competirmos para vencer um oponente em um debate filosófico.

Para Sócrates, a porção da psique que deveria ser cultivada para motivar nossas ações de um modo conforme a um bom caráter moral era o nous, muitas vezes chamado de "entendimento" ou "inteligência". Um estudo de $\mathrm{H}$. Teloh explica este cuidado com a mente, mencionado acima como uma "terapia" da psique, como um entendimento dos termos que expressam os valores morais. Segundo Teloh, uma virtude é um estado mental que causa e explica nosso comportamento e, assim, os estados mentais motivariam nossas ações já que a psique seria a fonte de todos os nossos movimentos (p. 34). Basicamente, o argumento de Teloh pode ser resumido da seguinte forma: as virtudes motivam nossas ações e nosso comportamento e nos conduzem à racionalidade enquanto os diálogos alimentam a psique para o bem ou para o mal. Portanto, um estado mental motiva e dá a razão para cada comportamento.

No diálogo Cármides, podemos ver um exemplo desse argumento quando Sócrates se depara com um jovem, o próprio Cármides, que busca conselhos sobre a cura de um mal físico específico e Sócrates lhe diz que não devemos tentar curar uma parte qualquer do corpo, seja que parte for, sem tentar curar nossa psique. Sócrates diz ao personagem Cármides que não curamos uma parte se não reconhecemos que a parte doente é um complemento do todo e lhe explica o que seria esse cuidado com o todo: todo o mal e todo o bem provêm da psique e dela dimanam e, portanto, precisamos tratar a psyque em primeiro lugar se queremos passar bem em nossa completude, mente e corpo. Nesse diálogo é dito que a "A psique se 
trata com belas conversas. É dessas conversas nasce nas mentes a prudência"(157ss.).

É muito interessante que no Cármides apareça o paralelo entre a medicina e a formação moral tal como a analogia entre os discursos e o remédio na passagem 464 do diálogo Górgias. Sobre este ponto, o estudo de Lain-Entralgo, La Curación pela Palavra en la Antiguedad Clásica, afirma que Platão é o inventor de uma psicoterapia verbal rigorosamente técnica, na qual a entrega da psique é um requisito prévio. ${ }^{1}$ Sejam "belas conversas" ou um termo contemporâneo usado no estudo citado, "psicoterapia", o "tratamento" de Sócrates vai ser aceito pelo estudante que dá nome ao diálogo Cármides e, como é sugerido ao final da obra, este "tratamento" deve conduzir a uma verdade. Isto implica outro conceito fundamental para a pedagogia e ética platônicas: a psicagogia. Platão define psicagogia como a "arte de conduzir as mentes através das palavras, mediante o discurso" (Fedro 261 a-b e 271 c-d). Este é também um conceito fundamental para a compreensão de toda a filosofia platônica uma vez que Platão chama de filosofia a própria atividade educativa, ligada a uma expressão escrita na forma de diálogo (Colli, p.9).

O diálogo filosófico apresenta o método dialético como o instrumento através do qual se pode adquirir o conhecimento. Mas a função do diálogo para a filosofia é maior: sua prática propicia o desenvolvimento de uma orientação filosófica para a vida do educando, formando-o moral e intelectualmente ao torná-lo capaz de adquirir um modo autônomo de pensar e agir. Para este fim, o diálogo filosófico conta com os elementos básicos de pergunta e resposta, afirmação e negação, prova e refutação, que são comuns a todas as formas de conversas e que propiciam uma postura ativa do educando, viabilizando um posterior pensamento crítico. O diálogo também implica elementos práticos como o conflito e o acordo, o elemento da reciprocidade no ensino e no aprender e, assim, pode-se entender que o mais importante nos diálogos são os sujeitos que aceitam a tarefa de dialogar filosoficamente e vencer os conflitos em nome do conhecimento. Tecnicamente, todos esses dados aparecem na dialética platônica como duas atividades fundamentais e complementares: (1) elenchia, geralmente traduzido como "refutação" mas que é tanto o argumento a refutar, quanto o próprio meio de refutação através de argumentos, cujo objetivo é combater as

11958, p. 155-197. Apud F. Oliveira, Cármides, 1981, p. 85 nota 21. 
opiniões sustentadas de modo dogmático para tornar possível a recepção das opiniões verdadeiras, tal como Sócrates procede ao "limpar" a psyque do estudante Cármides pela refutação (Cf. Cármides 154 e), e (2) a já mencionada psycagogia, ou "orientação da alma" de modo a possibilitar a aquisição de opiniões verdadeiras através de argumentos, sugestões, induções ou paradoxos (Cf. Teloh, p. 61).

Seguindo ainda o argumento de Teloh, podemos imaginar a psyque como uma teia de crenças e opiniões nas quais as mais empíricas estariam na periferia da teia, enquanto aquelas conectadas com as convicções e valores mais básicos do sujeito (que Teloh chama de visão geral da vida) estariam localizadas no centro. $\mathrm{O}$ que corresponderia à visão da vida que alguém pensa já ter formada em si é o que provoca Sócrates ao diálogo filosófico. Desse modo, percebemos alguns exemplos: o jovem Cármides orgulha-se de seu comportamento quieto, Eutifron leva a vida completamente voltada ao estudo das divindades de Homero, Laques acredita que o paradigma das ações de um guerreiro é enfrentar os perigos e morrer em seu posto quando preciso. Estas questões cruciais para esses interlocutores é o que motiva Sócrates a iniciar seus diálogos. Sócrates aborda seus interlocutores enfocando "seus valores mais básicos" e, uma que a "conversa" é iniciada, Sócrates passa a investigar e fazer seu interlocutor investigar conjuntamente se o que eles pensam ser verdade é de fato um conhecimento seguro. No diálogo Laques podemos entender a chamada "dialética negativa" ou elenchia nas próprias palavras de Laques: "quem vier a falar com Sócrates habitualmente, ainda que, de início, comece a discutir sobre algo diferente, inevitavelmente será arrastado para uma conversa em círculo, até cair em dar respostas sobre si próprio. Daí, Sócrates não mais o largará, antes de tudo ter posto à prova”.

É preciso que o interlocutor aceite investigar aquilo que diz acreditar como verdadeiro. Sócrates utiliza outro elemento, a ironia (eironeia). Segundo Scolnicov, buscar o conhecimento equivaleria a salvar sua própria vida dos enganos e preconceitos que confundiam o interlocutor até o encontro com Sócrates. Nesse processo, a ironia seria a "via indireta" que Sócrates percorre para fazer com que seu interlocutor chegue ao conhecimento ou a uma opinião verdadeira - como faz no Ménon - para que ele próprio possa "salvar-se". Sócrates constantemente fala demonstrando um certo desconhecimento sobre o tema e, com isso, busca convencer o interlocutor a falar sobre seu modo de vida e suas motivações morais. 
Scolnicov nos diz que tal ironia possui um objetivo bastante claro, a saber, "voltar o interlocutor para a filosofia, convencê-lo do valor de uma vida refletida", mas, alerta que isso tem que ser alcançado "por cada um, para si mesmo" porque "a ironia socrática nos leva ao desespero" já que entendemos as palavras no sentido ao qual estamos acostumados e tentamos entender a busca pelos sentidos mais precisos a que Sócrates nos conduz. Assim, ela "nos deixa defronte a um vácuo que nos cabe preencher por nossos próprios esforços, se formos capazes” (pp. 47-8).

Assim como a ironia busca fazer o interlocutor assumir o trabalho de investigar a si próprio, a psycagogia busca impulsionar as capacidades humanas naturais para que a reflexão e o pensamento crítico sejam possíveis. Como "orientação da psyque" a psycagogia é algo voluntariamente aceito e que não "preenche lacunas" com ensinamentos impostos ou transmissão de informações, mas apenas aponta um caminho para o conhecimento que pode sempre ser refeito.

\section{Educação, formação do caráter e motivação moral no diálogo $A$ \\ República}

Uma definição de dialética como psycagogia diz que deve haver uma técnica (techne) de guiar e de converter mais efetivamente a psyque. A psycagogia é explicada na República: "aceitando-se que a psique vê e que não olha para onde deveria, tal conhecimento especial deve fazê-la ver o que importa” (578 b). Orientar a psique é testar, conferir, avaliar as suas crenças. O objetivo seria transformar a mera crença em conhecimento através da sua avaliação em diferentes perspectivas, voltando-se várias vezes ao argumento e, finalmente, ajustando a crença a correntes firmes na mente (Ménon 85 c-d).

$\mathrm{O}$ vínculo entre educação e ética era fundamental no exercício filosófico de Platão e a "grande novidade que trazia era buscar na personalidade, no caráter moral, a medula da existência humana, em geral, e da vida coletiva, em particular" (Jaeger p. 374). As "coisas humanas" para as quais Sócrates e, depois, Platão, dirigiam atenção culminavam sempre no bem do conjunto social, do qual dependia a vida do indivíduo tal como em todas as visões éticas comunitaristas. Desse modo, um Sócrates que inspira Platão e cuja educação não fosse voltada à política e à ética não teria encontrado alunos na Atenas de seu tempo, segundo a doxografia de Xenofonte. No começo do segundo livro das Memoráveis, lemos um diálogo 
de Sócrates com Aristipo de Cirene que sustenta que toda educação deve ser política (Mem. II, 1). Nessa perspectiva, o homem deve ser educado para governar ou para ser governado. Aquele que for educado para governar tem de aprender a priorizar o cumprimento dos deveres à satisfação das necessidades físicas, ele deve aprender a se sobrepor à fome e à sede, ao frio e ao calor. Não deve temer qualquer trabalho, por mais difícil que venha a ser, tal como não teme investigar sua própria vida buscando o autoconhecimento.

Sócrates utiliza o termo askésis quando se refere a esta educação para o autodomínio na formação do caráter moral (Cf. Xenofonte, Mem. II, 1, 6). Askésis significa "exercício, prática, e, por extensão, gênero de vida" e está vinculada ao verbo askeo que tem como primeira significação "trabalhar materiais brutos" (Jaeger, p. 378), tal como Sócrates acreditava fazer com os estudantes ainda afeitos a explicações dogmáticas e pensamento acrítico. A educação com vinculada à ética e à política comunitarista é apresentada em outras passagens como Mem. II, 1, 13 e Mem. IV, 2, 11. Ela implica o aprendizado do autodomínio. Como vimos, um ponto central da ética socrática - e que influencia Platão em seus textos anteriores ao livro Leis - é o internalismo ou o modo de conceber a motivação moral como algo que parte da psyque do próprio indivíduo e, claramente não é a mera submissão exterior à lei, tal como exigia o conceito tradicional de justiça e que, de certo modo, será retomado nas Leis, último diálogo platônico.

O processo interior de motivação moral do agente no comunitarismo platônico reflete a vida coletiva e o conceito político de domínio na representação de uma pólis bem governada. $\mathrm{O}$ que deve residir na psyque como resultante do processo da formação do caráter é o que irá motivar as ações do agente, e, coincidentemente, trata-se também do bem da comunidade ou da pólis. Ao estudar esta questão na filosofia da educação de Platão, Gould argumenta que, para Platão, a função da educação é a formação de um caráter moral mais ajustado à organização da sociedade e, portanto, mais capaz de lidar com o caráter prescritivo das leis. A educação moldaria a vida interior dos membros da sociedade para fomentar o acordo com a vida exterior (p.111-2). Na interpretação de Gould, Platão apresenta o processo da formação do caráter moral iniciando-se desde o momento do nascimento: os medos infantis continuados, por exemplo, habituaria a criança à timidez e, assim, devem ser combatidos ao se movimentar o berço com ritmo induzindo a criança à calma. Se permitirmos que o medo domine a criança, o hábito da covardia tomaria posse da sua psyque. Portanto, a 
chave para este estágio inicial da educação estaria na askésis que consistiria em habituar a criança, desde seus primeiros momentos, ao modo de vida que se deseja para ela. Nesse nível, os processos mentais conscientes ainda não são observáveis e não podem ser percebidos conscientemente pela criança e, ainda assim, isso faz Platão acreditar que seria um erro supor que, por essa razão, a educação não precisaria ter início nesse período da infância. Isso coincide com os escritos de Kant sobre a educação. ${ }^{2} \mathrm{Na}$ maior parte dos homens, a consciência desenvolve-se muito mais tarde ou desenvolve-se de modo precário e, por consequência, as suas vidas não são motivadas pela razão consciente, mas pelas emoções mais internas. Isto pode acontecer desde muito cedo e não intervir para a formação da consciência e para o estímulo da autonomia e do pensamento crítico do aluno seria perder a esperança na formação de uma vida voltada para o bem. Desse modo, o objetivo principal seria fomentar na criança um temperamento tranquilo e propiciar a eupsiquia, uma mente em equilíbrio, tal como mencionamos no início desse artigo como bem-estar da psique (Cf. Gould p. 111-2).

No período em que Sócrates volta-se para as "coisas humanas", surge no idioma grego a nova palavra enkráteia que significa domínio de si mesmo, firmeza e moderação ${ }^{3}$. Tal palavra deriva do adjetivo enkratés que designa aquele que tem poder ou direito de dispor de alguma coisa. "E como o substantivo só aparece na acepção de domínio moral sobre si próprio e não se encontra nunca antes daquela época, fica a evidência que foi expressamente forjado para esta nova ideia” (Jaeger, p. 379). Segundo Xenofonte, na passagem Mem. I, 5, 4, a enkráteia não constitui uma virtude especial, mas “a base de todas as virtudes" uma vez que equivale a libertar o homem da tirania dos seus instintos. A rigor, este conceito vai trazer o germe do ordenamento político justo de Platão, trabalhado na República, e o conceito de justiça puramente interior em que se baseia tal ordenamento.

$\mathrm{Na}$ República, Platão apresenta um conceito de justiça que é alcançado pela psyque e também traça uma modificação na própria teoria

\footnotetext{
${ }^{2}$ Cf. OLIVEIRA,. "A educação na ética kantiana". Educação e Pesquisa, v. 30, n. 3, p. 447-460, set./dez. 2004; Cf. "Para inspirar confiança: considerações sobre a formação moral em Kant". Trans/Form/Ação, vol.29 n. 1, 2006.

${ }^{3}$ Cf. JAEGER, 1986, p. 379, com base nas suas pesquisas nas obras de F. STURZ, Lexicon Xenophonteum, voll, p. 14 e F. AST, Lexicon Platonicum, vol. I, p. 590. Diz Jaeger: "Como esta palavra se apresenta simultaneamente em Platão e Xenofonte, ambos discípulos de Sócrates, e também uma vez por outra em Isócrates, autor fortemente influenciado pela socrática, é conclusão irrefutável tratar-se de um novo conceito, cujas raízes mergulham no pensamento ético de Sócrates."
} 
sobre a psyque. Antes, em diálogos como o Fédon, apenas a razão vincula-se à psyque, enquanto todas as paixões e emoções eram colocadas como trabalhos do corpo na tentativa de trazer a psyque para a sua proximidade. Isto deveria, então, ser reprimido e a mente cultivada o mais amplamente possível como se estivesse já "livre do corpo". Este seria o conhecido "aprendizado da morte” que seria a ocupação própria do filósofo. Na República, Platão avançou para um reconhecimento de que esse conflito ocorre na própria psique. Este conflito interno seria então provocado pela tripartição natural da alma em (1) nous, a mais alta parte, e explicada como "a psyque quando todas suas energias estão direcionadas à aquisição da sabedoria”, (2) thymós, espírito ou humor, e (3) epithymía, apetite (República, 485). Dessa maneira, paixões e apetites são reconhecidos como tendo um lugar na vida humana: a atenção é direcionada para o equilíbrio mais que para a supressão deles. Contudo, no final da República, novamente fica explicitada a convicção de que o nous representa a psyque na sua mais verdadeira pureza e que o nous é caracterizado pela possessão do eros filosófico.

Contudo, como já sustentamos no início que o nous é o que deve ser cultivado na psyque e considerando que a filosofia de Platão é a própria busca do conhecimento configurada em uma atividade educativa, ou seja, o cuidado com a psique, retornamos aos conceitos anteriormente expostos: áskesis e enkráteia. Isto porque cultivar e educar vão sempre encontrar-se em suas definições: "Culto deriva de culturus: o que se vai trabalhar, o que se quer trabalhar, o que se quer cultivar. $O$ termo, na sua forma substantiva, aplicava-se tanto as labutas do solo, a agricultura, quanto ao trabalho feito no ser humano desde a infância; e nesta última acepção vertia romanamente o grego paidéia” (Bosi, p. 16). Assim, paidéia e cultivo da psique são trabalhos, esforços, exercícios ${ }^{4}$.

O diálogo República atribui uma ênfase especial ao trabalho e ao esforço educativo que devem ser dirigidos aos guardiões. Eles são vistos como as pessoas mais capazes da cidade e que, por isso, merecem a melhor educação. Esta deveria propiciar-lhes a formação para que consigam alcançar as virtudes dos líderes. J. Annas, em seu estudo específico sobre $A$ República, argumenta que Platão não oferece uma "filosofia da educação" que pode ser

${ }^{4}$ Cf. Teeteto, 153 b-c: 0 que se passa com a alma? Não é pelo estudo e exercício que também são movimentos, que ela adquire conhecimento, conserva-os e torna-se melhor, ao passo que com o repouso, a saber, pela falta de exercício e falta de aplicação, ou nada aprende ou esquece o que aprendeu? 
extraída do argumento sobre o Estado e que "muitos detalhes da sua proposta educativa interessam apenas aos estudantes da cultura grega". O seu trabalho cita os exemplos da "censura" a Homero e a preocupação platônica com os tipos de instrumentos musicais como interesses típicos dos estudos clássicos e não da filosofia. ${ }^{5}$ Mas ressalta também que "suas propostas sobre a forma e o conteúdo da educação trazem questões em filosofia e em educação que são claramente relevantes hoje” (p.80).

Segundo Annas, Platão é o primeiro pensador a defender sistematicamente a noção de que a educação é um treinamento do caráter, ao invés de uma aquisição de informações ou habilidades. Assim, a educação compreenderia "um treinamento total do caráter, uma educação de todos os aspectos nos quais as crianças são educáveis”. O processo de educação englobaria não apenas o conteúdo a ser aprendido, mas também o modo como se apresenta o que deve ser aprendido, a saber: o tipo de música que se ouve, o tipo de exercício que se faz, os tipos de objetos que estão à volta do educando (p. 82). Annas ressalta que na República existe uma falta de referência às conquistas acadêmicas. Não há referência a avaliações ou notas, mas as crianças são testadas para o fortalecimento do caráter moral (Cf. República 413c-d). A educação não é pensada como um processo de absorção de informações e habilidades que seriam periodicamente testadas, nem se considera uma pessoa bem educada como um prodígio em qualquer assunto ou em uma variedade de assuntos.

Como o mais importante na educação é a formação do caráter, Platão explica que existem dois aspectos cruciais do caráter. aquilo que é desenvolvido pelo treinamento físico e aquilo que é desenvolvido pelo que ele chama de mousike, que é melhor traduzido como "o treinamento nas artes" ou "treinamento intelectual”. Na passagem 410-412, argumenta-se sobre o equilíbrio entre o treinamento intelectual e o físico para produzir o tipo correto de caráter, e a moderação é enfatizada como uma necessidade em geral (401-3, 410e, 412a). Portanto, o caráter deve ser formado através de treinamento físico e treinamento intelectual: o treinamento físico destina-se também para o bem da mente e não do corpo (410c). E, tal como vimos anteriormente com o exemplo do diálogo Cármides, isso não implica que a

\footnotetext{
${ }^{5}$ Sobre a questão da natureza autoritária da educação regulada pelo Estado em Platão, ver Annas, 1981, p.89
} ss. 
mente deva se tornar separada do corpo, mas o corpo é que não pode ser esquecido na educação do caráter (Cf. Annas, pp. 84-5).

O educador deve criar as condições nas quais o tipo certo de mente possa desenvolver suas capacidades. Nas longas discussões dos estudos matemáticos que precedem a filosofia, existe uma ênfase constante na necessidade de todas as virtudes intelectuais: amplidão de visão, justeza de julgamento, agudeza nos argumentos e valorização do que é relevante. Os produtos finais da educação avançada dos guardiões são os filósofos. Nos filósofos a razão é mais plenamente desenvolvida e as leis devem basear-se na compreensão desses filósofos sobre os assuntos importantes para o bem-estar do Estado.

Finalmente, J. Annas apresenta uma dúvida sobre a capacidade intelectual das pessoas que na infância foram moldadas pelo treinamento pesado. Tais pessoas permaneceriam abertas para aceitar os valores morais da sua sociedade e permaneceriam livres para a criatividade e o pensamento crítico necessário aos estudos posteriores? Sua primeira resposta é dizer que a crença de Platão de que a matemática vem antes dos estudos mais aprofundados reforçaria a mente para o estudo posterior. Isso está de acordo com a República, 536e: "nenhum homem livre deve aprender algo de um modo escravizante”. O exercício obrigatório não compromete o corpo, mas o aprendizado forçado nunca permanece na mente. Annas argumenta que Platão talvez acreditasse que o tipo de pensamento que deve ser desenvolvido após o treinamento árduo - se não for obstado pelo mau ensino - é o pensamento do tipo puro e abstrato e relativamente independente dos resultados do treinamento moral anterior. Isso explicaria porque Platão pensa que a docilidade e a identificação com os valores do grupo não obstam um desenvolvimento posterior do pensamento original (pp.88-9).

Em um artigo intitulado Platonic Paideia, J. Gurley analisa especificamente o Livro VII da República e diz que o termo paidéia tal como usado por Platão implica o processo de um adolescente ou jovem que passa a ser homem e cidadão. ${ }^{6}$ Esse processo seria o caminho para se tornar "plenamente humano" e, uma vez que os cidadãos em Atenas eram somente

\footnotetext{
${ }^{6}$ Plato introduces Book VII of the Republic straightforwardly: 'Following after this,' I said, 'liken our nature to an experience such as follows concerning both education [paideias] and a lack of education [apaideusias].' (514a12) [Meta tauta de eipon apeikason toioutoi pathei ten hemeteran physin paideias te peri kai apaideusias.] (GURLEY, 1999, p. 352)
} 
aqueles do sexo masculino, a paidéia seria uma atividade centrada no gênero masculino e implicaria a iniciação do jovem à cidadania. A paidéia assegura a formação do homem e a preservação e viabilidade do grupo através da reprodução cultural e política (p. 356).

Sabemos que esses processos são peculiares ao comunitarismo e, contemporaneamente, seus defensores precisam enfrentar críticas muito bem construídas pelos filosófos igualitaristas que alegam a inviabilidade de uma tal concepção de educação em uma sociedade diversa e plural. Mas, para o que interessa nesse artigo, aceitamos que quando Platão discute "educação", ele defende uma forma de viver específica que seria uma reprodução de uma pólis justa, mesmo que seja "justa” apenas em pensamento.

\section{Educação, formação do caráter e motivação moral no diálogo Político.}

O diálogo Político, posterior à República, é considerado um dos diálogos que formam o conjunto final de diálogos de Platão, ou diálogos lógicos, e, nele, podemos testemunhar a própria prática do ensino da filosofia.

No diálogo podemos ver a figura de um interlocutor mais experiente que conduz as questões, chamado de o Estrangeiro de Eléia. Ele ensina a técnica dialética da divisão dos conceitos a um jovem aluno, homônimo de Sócrates e colega de estudos do jovem Teeteto (que dá nome ao diálogo anterior aos "diálogos lógicos" Sofista e Político). Um exemplo do ensino da técnica dialética pode ser verificado na passagem 276 d-e quando o Estrangeiro afirma que a erística deve ceder lugar para o rigor do procedimento dialético. $\mathrm{O}$ estrangeiro separa dentre os homens da pólis aqueles que administram outros homens "pela força" e aqueles cujas ordens são aceitas de boa vontade (como devem ser os guardiões mencionados na República). Ele retira da discussão o tirano e isola a figura daquele que chama de "verdadeiro político". Percebemos o treinamento na prática da dialética onde raciocínios lógicos conduzem ao maior rigor sobre afirmações sobre ética e política. Em 276e-277c, o Estrangeiro mostra ao educando os erros cometidos no processo de divisão e diz que o importante é que "educador" e "educando" cheguem juntos à mesma convicção sobre $o$ que discutem e sobre como realizam o diálogo.

No entanto, os exercícios e o esforço da aprendizagem cansam os educandos. Uma "aparente" tensão se apresenta quando o método parece já exaurir a questão para o jovem educando homônimo de Sócrates. Em 277c, o 
jovem Sócrates anseia por ouvir uma crítica à definição a que eles acabaram de chegar: "é preciso mostrar então o que, segundo crês, falta em nossa exposição.” Mas o objetivo do Estrangeiro é apontar as falhas do jovem interlocutor para levá-lo "do sono à vigília". Apesar da falta de paciência do jovem estudante, a ética pedagógica do Estrangeiro assegura que os espíritos capazes como o daquele estudante serão mais exigidos - como visto na República - e palavras e discursos frutificam na mente do ouvinte - como também foi afirmado no diálogo Cármides. Como se trata de educação nos moldes de Platão, o Estrangeiro busca a formação de um dialético competente e de um homem ético simultaneamente. Ocorre aqui algo semelhante ao que aconteceu no Fedro e o início da utilização do método da diaresis quando importava que aquele que soubesse vivenciar o treinamento viesse a se tornar um filósofo dialético e um profundo conhecedor das coisas dos homens. Tudo isso é apresentado porque a questão que dirige o diálogo não é apenas "quem é o verdadeiro político?", mas é também "como adquirir o verdadeiro conhecimento?”. Explicitamente em 277d, o Estrangeiro pergunta: "em que consiste em nós a ciência?”.

Para manter o jovem atento e ativo na "conversa", o recurso didático escolhido pelo Estrangeiro é o do uso do paradigma da tecedura que vem antecedido por uma frase do Estrangeiro que diz "poderíamos quase dizer que cada um de nós conhece todas as coisas como num sonho, mas que, à luz do despertar, se apercebe de nada saber" (277d). Recorrer ao "paradigma da tecedura" busca alcançar a verdade última sobre o político, sua forma ou ideia, já que "as realidades incorpóreas, que são as maiores e mais belas, revelam-se apenas à razão e somente a ela” (286 a).

Como um modo de alcançar o conhecimento das formas, o paradigma apresenta o reconhecimento e isolamento do elemento comum, a "forma única" no número de diferentes objetos particulares como o primeiro passo no processo de divisão para se chegar à ideia. Através do paradigma pode-se chegar a traçar a definição de uma Forma menos conhecida através do reconhecimento de elementos comuns presentes em uma Forma já conhecida. ${ }^{7}$ A definição de paradigma apresentada por Platão diz: "constitui um paradigma o fato de, ao encontrar-se um mesmo elemento em um grupo

7 Segundo Diès e Addam, a primeira ocorrência em Platão do termo paradeigma está na Apologia 23a significando "exemplo". A análise de Des Places acerca das ocorrências no diálogo Político fazem-no optar pelo termo "modelo" Diès (Nota No 1 p. 40); Addam (23 d-11, p. 29 e 120); Des Places (p.401). 
novo e bem distinto, aí interpretá-lo exatamente e, uma vez identificado nos dois grupos, permitir que ambos se incluam numa noção única e verdadeira" (278c). Esta definição coincide com o uso do termo "paradeigma” ensinado na República 472 b-c por Sócrates: "se descobrirmos a natureza da justiça, porventura entenderemos que o homem justo em nada lhe difere, mas em tudo lhe é semelhante? (...) foi para termos um paradigma que indagamos o que era a justiça e o que era um homem perfeitamente justo”.

Não há tensão entre a busca do que seja a ciência verdadeira, os procedimentos de tal busca e a intenção pedagógica. A educação na dialética implicava uma ética de sempre ouvir o interlocutor e provocar-lhe o raciocínio com refutações e demandas pela cogência dos argumentos, base para a formação do pensamento crítico. O Estrangeiro exemplifica isto com sua didática, e Marrou escreveu acerca deste ponto que, em Platão, "o ensino coincide com o método de investigação" (p.112). LoShan escreveu sobre este mesmo ponto que, embora "o enfoque manifesto dos diálogos" seja ético, o "enfoque latente é lógico e metodológico: eles são exibições dramáticas das tentativas de Sócrates para desenvolver - formular e analisar - os métodos e as técnicas do raciocínio sólido. Eles apresentam, do seu modo, um desempenho dramático das origens da lógica” (p. 33). E especificamente sobre a didática do uso de paradigmas no exercício dialético, Annas afirma que "há uma grande diferença entre aprender algo pela primeira vez e ter um entendimento pleno", como é o caso do jovem homônimo a Sócrates no seu tema sobre o político verdadeiro e a ciência do governante. De acordo com Annas, "é sempre uma boa ideia para o aprendiz usar recursos que podem ser descartados mais tarde quando ele possui, então, maestria no assunto e nos seus principais conceitos” (pp.80-1).

O paradigma da tecedura da lã como recurso didático no Político é escolhido porque nele podemos encontrar elementos comuns à técnica da política (279b). O Estrangeiro afirma que tenta conhecer a técnica da tecedura para, então, voltar ao que realmente lhe interessa: a técnica da política (Cf. 279e-280 a). Finalmente, após vários questionamentos ao jovem homônimo de Sócrates, ambos interlocutores chegam a uma definição de tecedura baseada no entrelaçamento da urdidura e da trama $(283 \text { a })^{8}$. No

\footnotetext{
${ }^{8} \mathrm{~A}$ urdidura implica o conjunto de fios dispostos no tear paralelamente ao seu comprimento, e por entre os quais passam os fios da trama; é urdimento ou urdume. A trama implica o conjunto dos fios passados no sentido transversal do tear, entre os fios da urdidura
} 
trabalho com a lã, as técnicas contrastantes de separação (cardar) e combinação (urdir) podem ajudar por analogia à compreensão sobre a organização da comunidade. Tal organização implicaria o "cardar" preliminar ou uma separação do cidadão mau do cidadão bom através de testes (paidia) e, em seguida, haveria o "urdir" de todos em um tecido harmonioso (308d-e). Basicamente, para Platão, o uso de paradigmas no treinamento do aluno visa "a detenção dos elementos comuns em compostos diferentes”, tal como ele explica quando crianças "aprendem letras e sílabas, depois aprendem a reconhecer as sílabas pequenas e fáceis e, em seguida, são apresentadas às outras que fazem com que errem na leitura. Por isso o professor põe as sílabas familiares antes das novas e aponta onde as mesmas letras ocorrem" (277d -278c).

Não é de estranhar que o exercício com tantas perguntas e respostas torne-se muito maçante para o jovem aluno, que finalmente interroga: "então, por que não dizer logo 'a tecedura é a arte de entrelaçar a urdidura e a trama' em lugar de fazer tantos rodeios e um acervo de distinções inúteis?” (283 a). Obviamente receber uma informação rápida e de modo acrítico é mais confortável que passar pelos procedimentos que levam ao pensamento crítico. Entretanto, a resposta do Estrangeiro de Eléia que guia o diálogo com o aluno não é rápida nem confortável. Sua resposta diz que "nada há de inútil” no que foi dito uma vez que apenas podemos saber se o diálogo travado foi desnecessário e demasiadamente prolongado se soubermos aquilo que realmente constituem o excesso e a falta. De acordo com o Estrangeiro "somente assim teremos uma regra para elogiar ou censurar, no momento próprio, o que for demasiado ou o que for muito pouco, nas conversas mantidas" (283c). E, o processo educativo prossegue com mais perguntas e respostas. Haverá, enfim, uma conclusão?

\section{Conclusão: A investigação filosófica como educação}

Sócrates e Platão enfocaram a ética como uma questão educativa e não como uma doutrina a ser inculcada nos jovens. Tratava-se de aprender a agir corretamente nas diversas situações da vida. Eles logo reconheceram que, para saber como agir, precisamos saber o que está envolvido nas escolhas. Desse modo, a ética une-se à busca de um conhecimento teórico. No Político e na República aprendemos que a ética e a política de Platão convertem-se em educação para o pensamento crítico e para a formação do caráter moral do 
jovem. O vínculo entre ética e educação é essencial. E se não for bastante a educação tradicional de "leitura dos poetas, música, ginástica", vimos que é preciso contrariar nossos desejos se estes forem insensatos ou injustos. Não se trata apenas de termos a motivação moral para agirmos com vistas a uma utilização prática imediata, mas o alvo a alcançar é sermos motivados por toda a vida para escolhermos ações justas que construam uma vida justa na sua inteireza. Escolhermos a cada momento implica estarmos dispostos a sempre investigar aquilo que motiva nossas escolhas, ou seja, estarmos dispostos a manter uma vida sempre sob investigação filosófica.

Temperamentos naturalmente gentis ou espirituosos são as matérias brutas com as quais tanto o político educado quanto o próprio filósofo educador trabalham, uma vez que os dois tipos de temperamento devem ser guiados pela razão nas técnicas de "urdidura" e "trama" do tecido social. Harmonizar os diferentes cidadãos é educação tanto na República (423e, 441e-42 a) quanto no Político (308d-e). A filosofia de Platão sustenta que os temperamentos distintos podem ser combinados em um único homem, a quem se deve atribuir uma posição de autoridade. $O$ equilíbrio de temperamentos é alcançado nos dois diálogos ao se reconhecer que a cidade contém tipos psicológicos contrastantes e devemos ensiná-los a viver juntos. Não é o violento e o intempestivo, nem o fraco e o indolente que possuem as virtudes da coragem ou da temperança. O Político não descreve um treinamento específico ao governante, tampouco nos instrui detalhadamente sobre sua técnica de legislar. Mas, ensina que o verdadeiro político tem que se exercitar continuamente para alcançar o conhecimento da "realidade verdadeira”, a Forma. Este conhecimento mais aprofundado não é adquirido sem também ser alcançada a força moral necessária para a participação política. Sobre este ponto, Vlastos anotou que "apenas aqueles que passaram pelo treinamento metódico, Platão creditaria competência para sustentar juízos autorizados acerca do certo e do errado na moral, sabendo-se que o conhecimento requer sempre a apreensão de formas eternas” (p. 138). Essa competência para expressar juízos sobre o certo e o errado é algo caro a Platão, especialmente considerando-se a lembrança constante do julgamento e condenação de Sócrates pelos tipos de homens descritos na Apologia.9 Ao político verdadeiro, que legisla e julga, Platão propõe o treinamento na

${ }_{9}^{9}$ Sobre este ponto específico, ver Mário Nogueira de Oliveira, "A defesa filosófica de Platão aos acusadores de Sócrates: considerações sobre os diálogos Apologia e Politico". HYPNOS, 13 (2004), p. 84-94. 
investigação filosófica que pressupõe o contato entre interlocutores que aceitam um esforço comum prolongado vivenciado em um ambiente de amizade e de não competição.

Sabemos que a compreensão de Platão sobre educação e formação moral é fruto da experiência vivida com um "professor" que não se dizia tal coisa para que não fosse confundido com alguém que doutrinava jovens incapazes de pensamento crítico. O "educador" Sócrates fez filosofia buscando na interlocução uma resposta possível às questões investigadas. P. Bonagura afirma que os textos de Platão apresentam a busca da verdade junto com a preocupação com o cultivo da psyque. Uma psyque cultivada, nos moldes platônicos, somente é alcançada com interlocução e dentro de um tempo prolongado (p.120). Os exercícios de lógica ou, para alguns, a argumentação maçante, eram a forma mais eficaz de se ter o aprendizado escrito na mente. Bonagura também alega que a essência do platonismo está em transpor o que é exterior para a psyque do aprendiz em um contínuo processo de estímulo para a psyque de cada um dos interlocutores enlaçando o saber teórico com o saber prático. Platão é o filósofo-educador que quer chegar ao outro não somente para fazê-lo entender o conteúdo daquele que fala, mas para que isto seja eficaz para o seu aperfeiçoamento moral (p. 315).

Tal como nos exercícios contemporâneos para a formação do pensamento crítico, Platão aprendeu com Sócrates que educar implica dois elementos fundamentais: (1) a necessidade de ser autêntico e viver o que se quer transmitir e (2) o fato de que só se possui a verdade quando podemos passá-la adiante, algo que vai ser afirmado posteriormente por Aristóteles na Metafisica I. Em outras palavras, quando se recebe passivamente informações ou doutrinas, o ouvinte nada tem a dizer, permanece acrítico. A resposta interior e ativa para aquilo que lhe é apresentado transforma-se em algo que ele genuinamente possui somente quando exerce o esforço para comunicar o que é pensado e aprendido. Ser acrítico equivaleria a - em termos contemporâneos - quase ser um analfabeto funcional. Por isso o Estrangeiro de Eléia, no Político, repreende tantas vezes o seu jovem interlocutor quando acatava com muita facilidade suas propostas - seja por estar apressado, cansado ou entediado.

Por parte do educador isso implica a generosidade de dar o melhor que se sabe aos outros, para que possa ser útil onde quer que encontre uma "terra fértil". Por parte do educando, aparece o desejo de falar sobre aquilo que está aprendendo. Mas, cabe ao primeiro, que sabe mais, estimular seu 
interesse, perguntando-lhe algo, ironizando, tecendo refutações para aprimorar seu pensamento crítico. O educador dialético convida o educando a responder o que lhe é perguntado e que lhe provoca a reflexão com algo em acordo com sua interioridade que está sendo trabalhada pelo exercício filosófico. Podemos perceber isso na figura de Sócrates na República e do Estrangeiro de Eléia no Político. Afinal, o fim de todo educador é que seus educandos cheguem a ser "autores", pessoas autônomas, capazes de construir seus próprios projetos de vida.

Especificamente sobre a educação do caráter, Noddings e Slote escreveram que é preciso que haja uma interação inteligente e cuidadosa entre adultos e crianças que, mesmo enfocando a prática, eduque e estimule o intelecto, estimule as virtudes sociais e emocionais e não apenas os valores morais tradicionais da comunidade (p. 351). Capacitar alguém para pensar criticamente e ser "autor" das suas próprias opiniões, convicções e justificativas para a vida que escolhe viver é o trabalho de um filósofo educador: aquele que, enquanto ensina algum conteúdo, transmite-o como um diálogo e uma prática de exercícios de modo que aquele que o recebe passe a amar e desfrutar esse conhecimento e possa interiorizá-lo e, então, comunicá-lo. Ao comunicar, o faz como um "novo autor" que foi "recriado em si mesmo" pela investigação filosófica que leva ao autoconhecimento e a possessão de um modo de pensar crítico e ético. ${ }^{10}$

Platão escreveu inspirado por um Sócrates que foi separado de Atenas por acreditar em outra forma de educação diferente daquela do seu contexto ateniense. Este evento foi chamado por alguns como a separação entre a filosofia e a cidade. Platão passou a entender que a finalidade última da educação é a de revogar as separações que obstam o bem-estar de todos e a coesão do tecido social.

${ }_{10}$ Veja-se a este respeito, Bonagura, 1991, p 330-1, e também seus comentários a Gonzalez-Simancas (1990) 


\section{Referências Bibliográficas}

ANNAS, J. An introduction to Plato's Republic. Oxford: Oxford University Press, 1981.

BONAGURA, P. Exterioridad y interioridad: la tensión filosófica-educativa de algunas páginas platônicas. Pamplona: Ediciones Universidad de Navarra, 1991.

BOSI, A. Dialética da Colonização. São Paulo: Companhia das Letras, 1992

COLLI, G. O Nascimento da Filosofia (Trad. Frederico Carotti). Campinas: Ed. Unicamp, 1988, p. 9.

GOULD, J. The Development of Plato's Ethics. Cambridge: Cambridge University Press, 1955.

GONZALEZ LASO, A. El Político. Madrid: Centro de Estudos Constitucionales, 1981.

GONZALEZ-SIMANCAS, J.L. Principios generales de la educación: apuntes de la asignatura de Pedagogía general. Pamplona, 1990

GURLEY, J. "Platonic Paideia”. Philosophy and Literature 23.2 (1999), p. 351-377.

IRWIN, T. Plato's Ethics. New York, Oxford: Oxford University Press, 1995. JAEGER, W. Paideia: A formação do homem grego (Trad. Artur M. Parreira). São Paulo: Martins Fontes, 1986

LOSHAN, Z. "Plato's counsel on education”. In: RORTY, A. (ed). Philosophers on education: new historical perspectives. London: Routledge, 2003, pp. 32-50.

MARROU, H.I. História da Educação na Antiguidade (Trad. Mário L. Casanova). São Paulo: EPU, 1975

NODDINGS, N. \& Slote, M. "Changing notions of the moral and of moral education” In.: Pholosophy of education. In: BLAKE, N. (ed.) et. all. Oxford: Blackwell, 2003.

OLIVEIRA, F. "Introdução,versão do grego e notas" de Platão, Cármides. Coimbra: Instituto nacional de Investigação Científica, 1981.

PLATÃO. Político (Trad. J. Paleikat e João Cruz Costa). São Paulo: Nova Cultural, 1987.

. The Statesman. Trad. H. Fowler. Cambridge: Cambridge University Press, 1975.

- A República (Trad. Maria Helena da Rocha Pereira). Lisboa: Fundação Calouste Guilbekian, 1987. 
SKEMP, J. B. Plato's Statesman. A translation of the Politicus of Plato with introduction, essays and footnotes. New Haven: Yale University press, 1952 SCOLNICOV, S. Platão e o problema educacional. São Paulo: Loyola, 2006. TELOH, H. The Development of Plato's Metaphysics. University Park: Pennsyvania State University, 1981.

VLASTOS, G. Socrates Ironist and Moral Philosopher. Cambridge: Cambridge University Press, 1991.

XENOFONTE. Ditos e Feitos Memoráveis de Sócrates II, 1 (Trad. Líbero Rangel de Andrade). São Paulo: Nova Cultural, 1987. 